\title{
SUPERVISI AKADEMIK DENGAN TEKNIK KLINIS UNTUK MENINGKATKAN KINERJA GURU \\ DALAM PEMBELAJARAN TEMATIK KURIKULUM 2013 \\ PADA SD SE-KECAMATAN GISTING
}

\author{
${ }^{1}$ Daryono, M.Pd, ${ }^{2}$ Nurhadi Kusuma, M.M, ${ }^{3}$ Muhtarom, M.Sc \\ email: daryonookke@gmail.com, nurhadikusuma87@gmail.com, muhtarom29@gmail.com
}

\begin{abstract}
This study begins with the condition of the implementation of the 2013 Curriculum thematic learning for grade 1 and 4 teachers in SD N 1 Gisting Permai, SD N 2 Gisting Permai and SD N 1 Gisting Atas who just implemented one semester is still not optimal and found various obstacles. This study aims to improve teacher performance in the 2013 curriculum thematic learning through clinical technical academic supervision and find out the magnitude of teacher performance improvement in the 2013 curriculum thematic learning after academic supervision activities with clinical techniques in SD Gisting Subdistrict even semester 2017/2018 academic year.

This research method refers to the procedure of action research (action research) carried out in three cycles for six meetings each cycle with the steps of planning, implementing actions, observing and reflecting.

The results of the academic supervision actions with clinical techniques for 3 cycles on the performance of the teacher in preparing RPP the final value of RPP in the first cycle averaged 77.8; cycle II averaged 81.8 and cycle III averaged 85.7 with a cumulative increase of 7.9 and the implementation of 2013 curriculum curriculum thematic class 1 and 4 teachers the final value of the first cycle averaged 77.2, cycle II on average 85.7 and cycle III averaged 90.7 with a cumulative increase of 13.5. Thus it was concluded that the increase in teacher performance in the 2013 curriculum thematic learning after akaedical supervision with clinical technique in the elementary school of Gisting Subdistrict in the semester of 2017/2018 school year and the magnitude of teacher performance improvement in the 2013 curriculum thematic learning after academic supervision with clinical techniques at the Elementary School Even semester Gisting for the 2017/2018 school year, namely the performance of teachers in compiling thematic RPPs cycles I, II, III experienced a cumulative increase of 7.9 and teacher performance in thematic learning had a cumulative increase of 13.5.
\end{abstract}

Keywords: Clinical supervision, RPP, thematic learning.

\section{ABSTRAK}

Penelitian ini diawali dari kondisi pelaksanaan pembelajaran tematik Kurikulum 2013 pada guru kelas 1 dan 4 pada SD N 1 Gisting Permai, SD N 2 Gisting Permai dan SD N 1 Gisting Atas yang baru melaksanakan satu semester masih belum maksimal dan menemukan berbagai kendala. Penelitian ini bertujuan untuk meningkatkan kinerja guru dalam pembelajaran tematik kurikulum 2013 melalui supervisi akademik teknis klinis dan mengetahuai besarnya peningkatan kinerja guru dalam pembelajaran tematik kurikulum 2013 sesudah kegiatan supervisi akademik dengan teknik klinis pada SD Kecamatan Gisting semester genap tahun pelajaran $2017 / 2018$.

Metode penelitian ini mengacu pada prosedur penelitian tindakan (action research) yang dilaksanakan dengan dalam tiga siklus selama enam pertemuan yang setiap siklus dengan langkah perencanaan, pelaksanaan tindakan, pengamatan dan refleksi.

Hasil dari tindakan supervisi akademik dengan teknik klinis selama 3 siklus terhadap kinerja guru dalam menyusun RPP nilai akhir RPP siklus I rata-rata 77,8; siklus II rata-rata 81,8 dan siklus III rata-rata 85,7 dengan peningkatan kumulatif 7,9 dan pelaksanaan pembelajaran tematik kurikulum 2013 guru kelas 1 dan 4 nilai akhir siklus I rata-rata 77,2, siklus II rata-rata 85,7 dan siklus III rata-rata 90,7 dengan peningkatan kumulatif 13,5. Dengan demikian disimpulkan bahwa peningkatan kinerja guru dalam pembelajaran tematik kurikulum 2013 setelah adanya supervisi akaedmik dengan teknis klinis pada SD Kecamatan Gisting semester genap tahun pelajaran 2017/2018 dan besarnya peningkatan kinerja guru dalam pembelajaran tematik kurikulum 2013 sesudah kegiatan supervisi akademik dengan teknik klinis pada SD Kecamatan Gisting semester genap tahun pelajaran 2017/2018, yaitu kinerja guru dalam menyusun RPP tematik siklus I, II, III mengalami peningkatan kumulatif 7,9 dan kinerja guru dalam pembelajaran tematik mengalami peningkatan kumulatif 13,5.

Kata Kunci: Supervisi klinis, RPP, pembelajaran tematik. 


\section{A. PENDAHULUAN}

Tujuan Pendidikan Nasional yang diamanahkan oleh Undang-Undang Sistem Pendidikan Nasional Nomor 20 Tahun 2003 adalah berkembangnya potensi peserta didik agar menjadi manusia yang beriman dan bertakwa kepada Tuhan Yang Maha Esa, berakhlak mulia, sehat, berilmu, cakap, kreatif, mandiri, dan menjadi warga negara yang demokratis serta bertanggung jawab (Syafaruddin, 2012).

Dalam pencapaian tujuan pendidikan sebagai garda terdepan yang menjadi ujung tombak adalah guru (Gazali, M., 2013). Guru sebagai pendidik professional mempunyai tugas utama mendidik, mengajar, membimbing, mengarahkan, melatih, menilai, dan mengevaluasi peserta didik pada jenjang dan jalur pendidikan yang menjadi beban tugasnya, seperti jenjang pendidikan anak usia dini jalur pendidikan formal, jenjang pendidikan dasar, dan jenjang pendidikan menengah (Yunanto, 2018).

Guru profesional ditandai dengan kompetensi merencanakan pembelajaran, melaksanakan pembelajaran, mengevalausi pembelajaran, dan melaksanakan tindak lanjut hasil pembelajaran serta melaksanakan kegiatan pengembangan keprofesian berkelajutan (Mahmudah, 2017). Di antara rangkaian kompetensi guru tersebut yang paling menentukan proses dan hasil belajar peserta adalah kompetensi guru dalam merencanakan pembelajaran dan melaksanakan proses pembelajaran (Saragih,. 2008).

Peraturan Menteri Pendidikan Nasional Republik Indonesia Nomor 22 tahun 2016 Tentang Standar Proses untuk Satuan Pendidikan Dasar Dan Menengah menyatakan proses pembelajaran pada satuan pendidikan diselenggarakan secara interaktif, inspiratif, menyenangkan, menantang, memotivasi peserta didik untu berpartisipasi aktif, serta memberikan ruang yang cukupbagi prakarsa,kreativitas, dan kemandirian sesuai bakat, minat dan perkembangan fisik serta psikologis peserta didik (Pendidikan, B. S. N. 2007). Untuk itu setiap satuan pendidikan melakukan perencanaan pembelajaran, pelaksanaan proses pembelajaran serta penilaian proses pembelajaran untuk meningkatkan efisiensi ketercapaian kompetensi kelulusan.

Dalam peraturan pemerintah nomor 32 tahun 2013 yang merupakan perubahan peraturan pemerintah nomor 19 tahun 2015 tentang Standar Nasional Pendidikan, dinyatakan bahwa standar proses adalah kriterian mengenai pelaksanaan pembelajaran pada satuan pendidikan untuk mencapai standar kompetensi kelulusan. Standar proses ini berlaku untuk jenjang pendidikan dasar dan menengah pada standar proses meliputi perencanaan proses pembelajaran, pelaksanaan proses pembelajaran, penilaian hasil pembelajaran, dan pengawasan proses pembelajaran untuk ter- laksananya proses pembelajaran yang efektif dan efisien.

Bahwa proses pembelajaran harus berlangsung interaktif, inspiratif, menyenangkan, menantang, dan merangsang aktivitas peserta didik untuk berpartisipasi aktif, serta memberikan ruang yang cukup bagi prakarsa, kreativitas, dan kemandirian sesuai dengan bakat, minat, dan perkembangan fisik serta psikologis peserta didik sesuai dengan kompetensi yang ada dalam kurikulum 2013 revisi tahun 2016 (Jiwa.I.W. dkk 2013) .

Proses pembelajaran tematik kurikulum 2013 revisi tahun 2016 yang telah dimulai pada kelas 1 dan kelas 4 pada awal tahun pelajaraan 201/2018, seharusnya guru sudah dapat menyesuaikan dalam perencanaan dan pelaksanaan kegiatan pembelajaran yang didesain dan dilakukan guru. Dengan kata lain bahwa guru harus mendesain perencanaan pembelajaran sebaik-baiknya agar pembelajaran tematik kurikulum 2013 terlaksana dengan baik (Hajar, I. 2013).

Namun kondisi demikian belum sepenuhnya tercapai pada seluruh sekolah binaan, hal ini didasarkan hasil pendampingan pelaksanaan kurikulum 2013 revisi 2016 pada kelas 1 dan 4 serta hasil supervisi pada semester ganjil 2017/2018 didapat bahwa pada guru kelas 1 SD N 1 Gisting Permai kualitas RPP Tematik yang disusun masih kategori cukup, pembelajaran kategori cukup; guru kelas 4 SD N 1 SD Gisting Permai kualitas RPP Tematik yang disusun masih kategori cukup, pembelajaran kategori cukup; guru kelas 1 SD N 2 Gisting Permai kualitas RPP Tematik yang disusun masih kategori cukup, pembelajaran kategori cukup; guru kelas 4 SD N 2 Gisting Permai kualitas RPP Tematik yang disusun masih kategori baik, pembelajaran kategori baik; guru kelas 1 SD N 1 Gisting Atas kualitas RPP Tematik yang disusun masih kategori cukup, pembelajaran kategori baik; guru kelas 4 SD N 1 Gisting Atas kualitas RPP Tematik yang disusun masih kategori cukup, pembelajaran kategori cukup.

Data kualitas RPP Tematik dan pelaksanaan pembelajaran tematik guru kelas 1 dan kelas $4 \mathrm{SD}$ Binaan dapat digambarkan dalam tabel berikut:

Tabel 1.1: Kualitas RPP tematik dan pembelajaran tematik guru kelas pada 3 sekolah binaan

\begin{tabular}{|c|c|c|c|c|c|}
\hline \multirow{2}{*}{$\begin{array}{c}\text { N } \\
\text { o }\end{array}$} & Nama & \multicolumn{2}{|c|}{ Guru Kelas 1 } & \multicolumn{2}{c|}{ Guru Kelas 4 } \\
\cline { 3 - 6 } & Sekolah & $\begin{array}{c}\text { RPP } \\
\text { Temati } \\
\mathrm{k}\end{array}$ & $\begin{array}{c}\text { Pemb } \\
\text { e- } \\
\text { lajara } \\
\mathrm{n}\end{array}$ & $\begin{array}{c}\text { RPP } \\
\text { Tema } \\
\text { tik }\end{array}$ & $\begin{array}{c}\text { Pemb } \\
\text { e- } \\
\text { lajara } \\
\mathrm{n}\end{array}$ \\
\hline 1. & $\begin{array}{c}\text { SD N 1 } \\
\text { Gisting } \\
\text { Permai }\end{array}$ & cukup & cukup & cukup & cukup \\
\hline 2. & SD N 2 & cukup & cukup & baik & baik \\
\hline
\end{tabular}




\begin{tabular}{|l|l|l|l|l|l|}
\hline & $\begin{array}{l}\text { Gisting } \\
\text { Permai }\end{array}$ & & & & \\
\hline 3. & $\begin{array}{l}\text { SD N 1 } \\
\text { Gisting } \\
\text { Atas }\end{array}$ & cukup & baik & cukup & cukup \\
\hline
\end{tabular}

Beberapa kendala yang menyebabkan kondisi seperti tersebut di atas diantaranya: usia guru yang mendekati pensiun sehingga menyebabkan informasi baru tentang pembelajaran tematik kurikulum 2013 revisi 2016 lambat meresponnya; kemampuan guru dalam tik juga menghambat dalam proses penyusunan RPP tematik; ketersediaan buku guru dan buku siswa revisi 2016 belum ada sehingga menyulitkan guru.

Berdasarkan beberapa hal di atas peneliti mencoba meningkatkan kompetensi guru dalam melaksanakan pembelajaran tematik kurikulum 2013 revisi 2016 pada semester genap tahun pelajaran 2017/2018 dengan melasanakan penelitian tindakan sekolah dengan judul " Supervisi Akademik Dengan Teknik Klinis Untuk Meningkatkan Kinerja Guru Dalam Pembelajaran Tematik Kurikulum 2013 Pada SD Kecamatan Gisting Tahun Pelajaran 2017/2018”

\section{B. TUJUAN}

Tujuan dar penelitian ini adalah untuk meningkatkan kinerja guru dalam pembelajaran tematik kurikulum 2013 melalui supervisi akademik teknis klinis dan mengetahuai besarnya peningkatan kinerja guru dalam pembelajaran tematik kurikulum 2013 sesudah kegiatan supervisi akademik dengan teknik klinis pada SD Kecamatan Gisting semester genap tahun pelajaran 2017/2018.

\section{METODE PENELITIAN}

1. Rancangan Penelitian

Penelitian tindakan ini dirancang menggunakan 3 siklus dengan 6 kali pertemuan, yaitu : (1) siklus pertama pertemuan pertama, (2) siklus pertama pertemuan kedua; (3) Siklus kedua pertemuan pertama, (4) Siklus kedua pertemuan kedua, (5) Siklus ketiga pertemuan pertama, (6) siklus ketiga pertemuan kedua, Tahapan kegiatan setiap siklus yang dilakukan yaitu; kegiatan refleksi (reflection), perencanaan(planing), pelaksanaan (action), dan observasi (observasing). Refleksi (reflection),

2. Subjek Penelitian

Subjek penelitian ini adalah guru Kelas pada SD N 1 Gisting Permai, SD N 2 Gisting Permai dan SD N 1 Gisting Atas Gisting Kabupaten Tanggamus semester Genap tahun pelajaran 2017/2018. Adapun Nama guru yang menjadi subyek penelitian teruang pada tabel 3.2 berikut:
Tabel 3.2 Nama guru subyek penelitian:

\begin{tabular}{|c|l|c|l|l|}
\hline $\begin{array}{c}\text { N } \\
\text { o. }\end{array}$ & \multicolumn{1}{|c|}{$\begin{array}{c}\text { Nama } \\
\text { Guru }\end{array}$} & $\begin{array}{c}\text { NUPT } \\
\text { K }\end{array}$ & Sekolah & $\begin{array}{c}\text { Mengaj } \\
\text { ar }\end{array}$ \\
\hline 1. & Sulasmi, & 743473 & SD N 1 & Kelas 1 \\
& S.Pd. & $\begin{array}{c}763830 \\
0013\end{array}$ & $\begin{array}{l}\text { Gisting } \\
\text { Permai }\end{array}$ & \\
\hline 2. & Sukoco & 464173 & SD N 1 & Kelas 4 \\
& & 964120 & Gisting & \\
& & 0032 & Permai & \\
\hline 3. & Supariyem & 105373 & SD N 2 & Kelas 1 \\
& , S.Pd. & 964330 & Gisting & \\
\hline 4. & Sumarni, & 525474 & SD N 2 & Kelas 4 \\
& S.Pd. & 364630 & Gisting & \\
& & 0003 & Permai & \\
\hline 5. & Kasij & 305673 & SD N 1 & Kelas 1 \\
& Djaman, & 663730 & Gisting & \\
& S.Pd. & 0003 & Atas & \\
\hline 6. & Gunarto, & 654474 & SD N 1 & Kelas 4 \\
& S.Pd. & 664720 & Gisting & \\
& & 0012 & Atas & \\
\hline
\end{tabular}

Sumber data penelitian ini adalah:

1. Produk perencanaan pembelajaran yang disusun guru

2. Pelaksanaan pembelajaran

3. Teknik Pengumpulan Data Penelitian

Teknik pengumpulan data dalam penelitian tindakan sekolah ini dilakukan dengan cara pengamatan atauobervasi. Teknik pengumpulan data menggunakan penilaian produk RPP untuk mengetahui kualitas RPP dan observasi pelaksanaan pembelajaran tematik untuk mengetahui kualitas pembelajaran tematik.

\section{PEMBAHASAN}

1. Deskripsi Hasil Siklus I Deskripsi Hasil Siklus I Pertemuan Pertama a. Perencanaan

Kegiatan tindakan pada siklus I pertemuan pertama direncanakan dengan langkah berikut:

1) Pengawas menyiapkan bahan RPP dan Pelaksanaan pembeajaran tematik: tentang peraturan standar proses, standar penilaian;

2) Pengawas menyiapkan isntrumen penilaian RPP tematik;

3) Guru menyiapkan RPP tematik yang akan disupervisi;

4) Pengawas mendampingi guru dalam merevisi RPP;

5) Pengawas menyiapkan instrumen supervisi pelaksanaan pembelajaran;

6) Pengawas dan guru menyepakati hal yang akan disupervisi dan instrumen supervisi pelaksanaan pembelajaran; 
7) Mempersiapkan tindak lanjut pertemuan berikutnya

\section{b. Pelaksanaan}

Pelaksanaan kegiatan supervisi akademik dengan teknik klinis pada siklus I pertemuan pertama dilaksanakan dengan langkah:

1) Pengawas menyampaikan maksud dan tujuan;

2) Pengawas bersama guru mencermati RPP tematik yang dimiliki guru

3) Pengawas memberikan penilaian pada RPP guru Diskusi penyempurnaan RPP tematik

4) Pengawas dan guru bersama-sama membicarakan rencana tentang materi observasi yang akan dilaksanakan.

5) Menentukan jenis data mengajar yang akan diobservasi dan dicatat selama pelajaran berlangsung yang tertuang dalam instrumen pengamatan proses pembelajaran tematik

6) Pengawas bersama guru melaksanakan refleksi

\section{c. Hasil Pengamatan}

Dalam melaksanakan kegiatan pendampingan peneliti didampingi sejawat melakukan observasi. Pada pertemuan pertama observasi terhadap kegiatan dan penilaian terhadap produk RPP tematik yang akan digunakan dalam supervisi klinis dalam pembelajaran. Penilian RPP tematik menggunakan format penilian RPP tematik.

Hasil pengamatan pada siklus I pertemuan pertama berfokus pada penilaiaan RPP tematik pada guru kelas I dan IV dengan hasil tertuang pada tabel 4.1 berikut:

\begin{tabular}{|c|l|c|c|c|}
\hline No. & \multicolumn{1}{|c|}{ Nama } & Skor & Nilai & Kategori \\
\hline 1. & Sulasmi, S.Pd. & 142 & 74 & Cukup \\
\hline 2. & Sukoco & 148 & 77 & Baik \\
\hline 3. & $\begin{array}{l}\text { Supariyem, } \\
\text { S.Pd. }\end{array}$ & 149 & 78 & Baik \\
\hline 4. & Sumarni, S.Pd. & 160 & 83 & Baik \\
\hline 5. & $\begin{array}{l}\text { Kasij Djaman, } \\
\text { S.Pd. }\end{array}$ & 156 & 81 & Baik \\
\hline 6. & Gunarto, S.Pd. & 142 & 74 & Cukup \\
\hline & Rata-rata & 149,9 & 77,8 & \\
\hline
\end{tabular}

Kemudian hasil penilaian RPP dalam rekap rantang nilai menggunakan tabel berikut 4.3:

Tabel 4.3: Rekapitulasi Nilai Hasil Penilaian RPP tematik siklus I

\begin{tabular}{|c|c|c|c|c|}
\hline N0 & Rentang & $\begin{array}{c}\text { Jumlah } \\
\text { Peserta }\end{array}$ & $\begin{array}{c}\text { Persent } \\
\text { ase }\end{array}$ & Sebutan \\
\hline 1. & $91-100$ & - & - & $\begin{array}{c}\text { Sangat } \\
\text { Baik }\end{array}$ \\
\hline 2. & $79-90$ & 2 & $33 \%$ & Baik \\
\hline 3. & $50-78$ & 4 & $67 \%$ & Cukup \\
\hline 4. & $0-49$ & - & - & $\begin{array}{c}\text { Perlu } \\
\text { bimbingan }\end{array}$ \\
\hline \multicolumn{2}{|c|}{ Jumlah } & 6 & $100 \%$ & \\
\hline
\end{tabular}

Dengan demikian kualitas RPP tematik yang dapat disusun oleh 6 guru pada 3 SD binaan pada siklus I dihasilkan 33\% kategori baik (2 orang) dan $67 \%$ kategori cukup (4 orang).

d. Evaluasi dan Refleksi

Dari hasil penampingan klinis pada penyusunan RPP tematik setelah hasil pengamatan dan penilaian atas produk RPP tematik masih terdapat beberapa kelemahan dan kekurangan yaitu aspek yang masih memiliki skor 2

Aspek lain yang masih memperoleh skor 3 sebanyak 20 aspek juga perlu diperbaiki agar manjadi skor 4.

Kelemahan dan kekurangan dalam penyusunan RPP tematik tersebut dijadikan acuan untuk merencanakan dan melaksanakan kegiatan berikutnya.

\section{Deskripsi siklus I pertemuan ke dua}

a. Perencanaan siklus I pertemuan ke dua

1) Pengawas menyiapkan isntrumen penilaian RPP tematik;

2) Guru menyiapkan RPP tematik yang akan disupervisi;

3) Pengawas menyiapkan instrumen supervisi pelaksanaan pembelajaran;

4) Pengawas dan guru menyepakati hal yang akan disupervisi dan instrumen supervisi pelaksanaan pembelajaran;

5) Mempersiapkan tindak lanjut pertemuan berikutnya;

b. Pelaksanaan

1) Pengawas menyampaikan maksud dan tujuan;

2) Pengawas menyampaikan materi observasi yang akan dilaksanakan dalam pembelajaran tematik;

3) Pengawas mengobservasi pelaksanaan pembelajaran tematik sesuai instrumen yang telah ditetapkan;

4) Pengawas melaksanakan supervisi klinis pelaksanaan pembelajaran tematik;

5) Pengawas bersama guru melaksanakan refleksi;

6) Tindak lanjut pertemuan berikutnya

\section{c. Hasil Pengamatan}

Dalam melaksanakan kegiatan pendampingan peneliti didampingi sejawat melakukan observasi. Pada pertemuan ke dua observasi terhadap proses pembelajaran tematik menggunakan format penilian pelaksanaan pembelajaran tematik. Hasil pengamatan terhadap proses pembelajaran tematik pada siklus II teranngkum dalam tabel berikut:

Tabel 4.5: Nilai penilaian pelaksanaan pembelajaran tematik pada siklus I

\begin{tabular}{|c|l|c|c|c|}
\hline No. & \multicolumn{1}{|c|}{ Nama } & Skor & Nilai & Kategori \\
\hline 1. & Sulasmi, S.Pd. & 72 & 78 & Cukup \\
\hline 2. & Sukoco & 72 & 78 & Cukup \\
\hline 3. & $\begin{array}{l}\text { Supariyem, } \\
\text { S.Pd. }\end{array}$ & 68 & 74 & Cukup \\
\hline 4. & Sumarni, & 77 & 84 & Baik \\
\hline
\end{tabular}




\begin{tabular}{|c|l|c|c|c|}
\hline & S.Pd. & & & \\
\hline 5. & $\begin{array}{l}\text { Kasij Djaman, } \\
\text { S.Pd. }\end{array}$ & 71 & 77 & Cukup \\
\hline 6. & Gunarto, S.Pd. & 66 & 72 & Cukup \\
\hline \multicolumn{2}{|r|}{ Rata-rata } & 71 & 77,7 & \\
\hline
\end{tabular}
pembelajaran tematik pada siklus I direkap dalam rantang nilai menggunakan tabel berikut 4.6:

Tabel 4.6: Rekapitulasi nilai pelaksanaan pembelajaran tematik siklus I

\begin{tabular}{|c|c|c|c|c|}
\hline N0 & Rentang & $\begin{array}{l}\text { Jumlah } \\
\text { Peserta }\end{array}$ & $\begin{array}{l}\text { Persent } \\
\text { ase }\end{array}$ & Sebutan \\
\hline 1. & $91-100$ & - & - & $\begin{array}{c}\text { Sangat } \\
\text { Baik }\end{array}$ \\
\hline 2. & $79-90$ & 1 & $17 \%$ & Baik \\
\hline 3. & $50-78$ & 5 & $83 \%$ & Cukup \\
\hline 4. & $0-49$ & - & - & $\begin{array}{c}\text { Perlu } \\
\text { bimbing } \\
\text { an } \\
\end{array}$ \\
\hline \multicolumn{2}{|c|}{ Jumlah } & 6 & $100 \%$ & \\
\hline
\end{tabular}
pelaksanaan pembelajaran tematik siklus I memperoleh nilai baik 1 orang $(17 \%)$ dan 5 orang cukup (83\%)

\section{d. Evaluasi dan Refleksi}

Evaluasi pengamatan pelaksananaan pembelajaran tematik pada guru kelas 1 dan kelas 4 pada 3 Sekolah Dasar pad siklus I ditemukan beberapa kelemahan atau kekurangan pada setiap aspek pengamatan. Skor pada setiap aspek yang memperoleh skor 2 menjadikan kelemahan yang perlu diadakan perbaikan.

Di samping skor 2 pada aspek yang diamati juga untuk perolehan skor 3 belum maksimal perlu ditingkatkan pada siklus II agar mencapai skor maksimal yaitu 4 .

\section{Deskripsi Hasil Siklus II \\ Deskripsi Siklus II Pertemuan Pertama a.Perencanaan}

1) Pengawas menyiapkan bahan RPP dan Pelaksanaan pembeajaran tematik: tentang peraturan standar proses, standar penilaian;

2) Pengawas menyiapkan isntrumen penilaian RPP tematik;

3) Guru menyiapkan RPP tematik yang akan disupervisi

4) Pengawas mendampingi guru dalam merevisi RPP

5) Pengawas menyiapkan instrumen supervisi pelaksanaan pembelajaran

6) Pengawas dan guru menyepakati hal yang akan disupervisi dan instrumen supervisi pelaksanaan pembelajaran

7) Mempersiapkan tindak lanjut pertemuan berikutnya

\section{b. Pelaksanaan}

1) Pengawas menyampaikan maksud dan tujuan;

2) Pengawas bersama guru mencermati RPP tematik yang dimiliki guru;
3) Pengawas memberikan penilaian pada RPP guru;

4) Diskusi penyempurnaan RPP tematik;

5) Pengawas dan guru bersama-sama membicarakan rencana tentang materi observasi yang akan dilaksanakan;

6) Pada tahap ini dibicarakan dan ditentukan jenis data mengajar yang akan diobservasi dan dicatat selama pelajaran berlangsung yang tertuang dalam instrumen pengamatan proses pembelajaran tematik;

7) Pengawas bersama guru melaksanakan refleksi

\section{c. Hasil Pengamatan}

Dalam melaksanakan kegiatan pendampingan peneliti didampingi sejawat melakukan observasi. Pada pertemuan pertama observasi terhadap kegiatan dan penilaian terhadap produk RPP tematik yang akan digunakan dalam supervisi klinis dalam pembelajaran. Penilian RPP tematik menggunakan format penilian RPP tematik

Hasil pengamatan pada siklus II pertemuan pertama berfokus pada penilaiaan RPP tematik pada guru kelas I dan IV dengan hasil tertuang pada tabel berikut

Tabel 4.8: Nilai Hasil Penilaian RPP Tematik siklus

\begin{tabular}{|c|c|c|c|c|}
\hline \multicolumn{5}{|c|}{ II } \\
\hline No. & Nama & Skor & Nilai & Kategori \\
\hline 1. & Sulasmi, S.Pd. & 153 & 80 & Baik \\
\hline 2. & Sukoco & 156 & 81 & Baik \\
\hline 3. & $\begin{array}{l}\text { Supariyem, } \\
\text { S.Pd. }\end{array}$ & 155 & 81 & Baik \\
\hline 4. & Sumarni, S.Pd. & 165 & 86 & Baik \\
\hline 5. & $\begin{array}{l}\text { Kasij Djaman, } \\
\text { S.Pd. }\end{array}$ & 162 & 84 & Baik \\
\hline 6. & Gunarto, S.Pd. & 151 & 79 & Baik \\
\hline & Rata-rata & 157 & 81,8 & \\
\hline
\end{tabular}

Kemudian hasil penilaian RPP dalam rekap rantang nilai menggunakan tabel berikut 4.9:

Tabel 4.9: Rekapitulasi Nilai Hasil Penilaian RPP Tematik siklus II

\begin{tabular}{|c|c|c|c|c|}
\hline N0 & Rentang & $\begin{array}{c}\text { Jumlah } \\
\text { Peserta }\end{array}$ & $\begin{array}{c}\text { Persent } \\
\text { ase }\end{array}$ & Sebutan \\
\hline 1. & $91-100$ & - & - & $\begin{array}{c}\text { Sangat } \\
\text { Baik }\end{array}$ \\
\hline 2. & $79-90$ & 6 & $100 \%$ & Baik \\
\hline 3. & $50-78$ & - & - & Cukup \\
\hline 4. & $0-49$ & - & - & $\begin{array}{c}\text { Perlu } \\
\text { bimbing } \\
\text { an }\end{array}$ \\
\hline \multicolumn{2}{|r|}{ Jumlah } & 6 & $100 \%$ & \\
\hline
\end{tabular}

\section{d. Evaluasi dan Refleksi}

Dari hasil penampingan klinis pada penyusunan RPP tematik hasil penilaian atas produk RPP tematik pada siklus II masih terdapat beberapa kelemahan dan kekurangan yaitu aspek yang masih memiliki skor 2 
Aspek lain yang masih memperoleh skor 3 sebanyak 30 aspek juga perlu diperbaiki agar manjadi skor 4.

Kelemahan dan kekurangan dalam penyusunan RPP tematik tersebut dijadikan acuan untuk merencanakan dan melaksanakan kegiatan berikutnya.

\section{Deskripsi Siklus II Pertemuan ke dua}

a. Perencanaan

1) Pengawas menyiapkan isntrumen penilaian pelaksanaan pembelajaran tematik

2) Guru menyiapkan RPP tematik yang akan disupervisi

3) Pengawas dan guru menyepakati hal yang akan disupervisi dan instrumen supervisi pelaksanaan pembelajaran

b. Pelaksanaan

1) Pengawas menyampaikan maksud dan tujuan;

2) Pengawas menyampaikan materi observasi yang akan dilaksanakan dalam pembelajaran tematik

3) Pengawas mengobservasi pelaksanaan pembelajaran tematik sesuai instrumen yang telah ditetapkan

4) Pengawas melaksanakan supervisi klinis pelaksanaan pembelajaran tematik

5) Pengawas bersama guru melaksanakan refleksi

6) Tindak lanjut pertemuan berikutnya

c. Hasil Pengamatan

Pada pertemuan ke dua observasi terhadap proses pembelajaran tematik menggunakan format penilian pelaksanaan pembelajaran tematik. Hasil pengamatan terhadap proses pembelajaran tematik pada siklus II terangkum dalam tabel berikut:

Tabel 4.11: Nilai penilaian pelaksanaan pembelajaran tematik pada siklus II

\begin{tabular}{|c|c|c|c|c|}
\hline No. & Nama & Skor & Nilai & Kategori \\
\hline 1. & Sulasmi, S.Pd. & 80 & 87 & Baik \\
\hline 2. & Sukoco & 77 & 84 & Baik \\
\hline 3. & $\begin{array}{l}\text { Supariyem, } \\
\text { S.Pd. }\end{array}$ & 76 & 83 & Baik \\
\hline 4. & Sumarni, S.Pd. & 84 & 91 & $\begin{array}{c}\text { Sangat } \\
\text { Baik }\end{array}$ \\
\hline 5. & $\begin{array}{l}\text { Kasij Djaman, } \\
\text { S.Pd. }\end{array}$ & 82 & 89 & Baik \\
\hline 6. & Gunarto, S.Pd. & 74 & 80 & Baik \\
\hline & Rata-rata & 78,8 & 85,7 & \\
\hline
\end{tabular}

Kemudian hasil penilaian pelaksanaan pembelajaran tematik pada siklus I direkap dalam rantang nilai menggunakan tabel 4.12 berikut:

Tabel 4.12: Rekapitulasi nilai pelaksanaan

pembelajaran tematik siklus II

\begin{tabular}{|c|c|c|c|c|}
\hline N0 & Rentang & $\begin{array}{c}\text { Jumlah } \\
\text { Peserta }\end{array}$ & $\begin{array}{c}\text { Persent } \\
\text { ase }\end{array}$ & Sebutan \\
\hline 1. & $91-100$ & 1 & $17 \%$ & $\begin{array}{c}\text { Sangat } \\
\text { Baik }\end{array}$ \\
\hline 2. & $79-90$ & 5 & $83 \%$ & Baik \\
\hline 3. & $50-78$ & - & - & Cukup \\
\hline 4. & $0-49$ & - & - & Perlu \\
\hline
\end{tabular}

\section{Deskripsi Hasil Siklus III}

\section{Deskripsi Siklus III Pertemuan Pertama}

\section{a. Perencanaan}

1) Pengawas menyiapkan bahan RPP dan Pelaksanaan pembeajaran tematik: tentang peraturan standar proses, standar penilaian;

2) Pengawas menyiapkan isntrumen penilaian RPP tematikGuru menyiapkan RPP tematik yang akan disupervisi

4) Pengawas mendampingi guru dalam merevisi RPP

5) Pengawas menyiapkan instrumen supervisi pelaksanaan pembelajaran

6) Pengawas dan guru menyepakati hal yang akan disupervisi dan instrumen supervisi pelaksanaan pembelajaran

7) Mempersiapkan tindak lanjut pertemuan berikutnya

\section{b. Pelaksanaan Tindakan}

1) Pengawas menyampaikan maksud dan tujuan;

2) Pengawas bersama guru mencermati RPP tematik yang dimiliki guru

3) Pengawas memberikan penilaian pada RPP guru

4) Pengawas mendampingi guru dalam menyempurnakan RPP tematik

5) Pengawas dan guru bersama-sama membicarakan rencana tentang materi observasi yang akan dilaksanakan.

6) Pada tahap ini dibicarakan dan ditentukan jenis data mengajar yang akan diobservasi dan dicatat selama pelajaran berlangsung yang tertuang dalam instrumen pengamatan proses pembelajaran tematik

7) Pengawas bersama guru melaksanakan refleksi

\section{c. Hasil Pengamatan}

Dalam melaksanakan kegiatan pendampingan peneliti didampingi sejawat melakukan observasi. Pada pertemuan pertama observasi terhadap kegiatan dan penilaian terhadap produk RPP tematik yang akan digunakan dalam supervisi klinis dalam pembelajaran. Penilian RPP tematik menggunakan format penilian RPP tematik 
Tabel 4.14: Nilai Hasil Penilaian RPP Tematik siklus

\begin{tabular}{|c|c|c|c|c|}
\hline \multicolumn{5}{|c|}{ III } \\
\hline No. & Nama & Skor & Nilai & $\begin{array}{c}\text { Katego } \\
\text { ri }\end{array}$ \\
\hline 1. & Sulasmi, S.Pd. & 159 & 83 & Baik \\
\hline 2. & Sukoco & 163 & 85 & Baik \\
\hline 3. & $\begin{array}{l}\text { Supariyem, } \\
\text { S.Pd. }\end{array}$ & 161 & 84 & Baik \\
\hline 4. & Sumarni, S.Pd. & 178 & 93 & $\begin{array}{c}\text { Sangat } \\
\text { Baik }\end{array}$ \\
\hline 5. & $\begin{array}{l}\text { Kasij Djaman, } \\
\text { S.Pd. }\end{array}$ & 167 & 87 & Baik \\
\hline 6. & Gunarto, S.Pd. & 158 & 82 & Baik \\
\hline & Rata-rata & 164,3 & 85,7 & \\
\hline
\end{tabular}

Kemudian hasil penilaian RPP dalam rekap rantang nilai menggunakan tabel berikut 4.15.:

Tabel 4.15: Rekapitulasi Nilai Hasil Penilaian RPP siklus III

\begin{tabular}{|c|c|c|c|c|}
\hline N0 & Rentang & $\begin{array}{c}\text { Jumlah } \\
\text { Peserta }\end{array}$ & $\begin{array}{c}\text { Persent } \\
\text { ase }\end{array}$ & Sebutan \\
\hline 1. & $91-100$ & 2 & $33 \%$ & $\begin{array}{c}\text { Sangat } \\
\text { Baik }\end{array}$ \\
\hline 2. & $79-90$ & 4 & $67 \%$ & Baik \\
\hline 3. & $50-78$ & - & - & Cukup \\
\hline 4. & $0-49$ & - & - & $\begin{array}{c}\text { Perlu } \\
\text { bimbinga } \\
\mathrm{n}\end{array}$ \\
\hline \multicolumn{2}{|c|}{ Jumlah } & 6 & $100 \%$ & \\
\hline
\end{tabular}

\section{d. Evaluasi dan Refleksi}

Dari hasil penampingan klinis pada penyusunan RPP tematik hasil penilaian atas produk RPP tematik pada siklus III masih terdapat beberapa kelemahan dan kekurangan tetapi sudah sangat sedikit.

Pada silklus III kelemahan dan kekurangan dalam penyusunan RPP tematik sudah sangat sedikit dari 6 guru, 1 orang guru sudah mencapai amat baik dan 5 guru sudah mencapai baik dengan nilai minimal 82 . Sehingga pendampingan penyusunan dihentikan pada siklus III

\section{Deskripsi Siklus III Pertemuan ke dua}

\section{a. Perencanaan}

(1) Pengawas menyiapkan isntrumen penilaian RPP tematik

(2) Guru menyiapkan RPP tematik yang akan disupervisi

(3) Pengawas menyiapkan instrumen supervisi pelaksanaan pembelajaran

(4) Pengawas dan guru menyepakati hal yang akan disupervisi dan instrumen supervisi pelaksanaan pembelajaran

(5) Mempersiapkan tindak lanjut pertemuan berikutnya

\section{b. Pelaksanaan Kegiatan}

(1) Pengawas menyampaikan materi observasi yang akan dilaksanakan dalam pembelajaran tematik
(2) Pengawas mengobservasi pelaksanaan pembelajaran tematik sesuai instrumen yang telah ditetapkan

(3) Pengawas melaksanakan supervisi klinis pelaksanaan pembelajaran tematik

(4) Pengawas bersama guru melaksanakan refleksi

\section{c. Hasil Pengamatan}

Hasil pengamatan pelaksanaan pembelajaran siklus III pertemuan ke dua terangkum dalam tabel berikut:

Tabel 4.17: Nilai penilaian pelaksanaan pembelajaran tematik pada siklus II

\begin{tabular}{|c|l|c|c|c|}
\hline No. & \multicolumn{1}{|c|}{ Nama } & Skor & Nilai & Kategori \\
\hline 1. & Sulasmi, S.Pd. & 83 & 90 & Baik \\
\hline 2. & Sukoco & 82 & 89 & Baik \\
\hline 3. & $\begin{array}{l}\text { Supariyem, } \\
\text { S.Pd. }\end{array}$ & 81 & 88 & Baik \\
\hline 4. & Sumarni, S.Pd. & 89 & 97 & $\begin{array}{c}\text { Sangat } \\
\text { Baik }\end{array}$ \\
\hline 5. & $\begin{array}{l}\text { Kasih Djaman, } \\
\text { S.Pd. }\end{array}$ & 85 & 92 & $\begin{array}{c}\text { Sangat } \\
\text { Baik }\end{array}$ \\
\hline 6. & Gunarto, S.Pd. & 81 & 88 & Baik \\
\hline & Rata-rata & 83,5 & 90,7 & \\
\hline
\end{tabular}

Kemudian hasil penilaian pelaksanaan pembelajaran tematik pada siklus III direkap dalam rantang nilai menggunakan tabel 4.18 berikut:

Tabel 4.18: Rekapitulasi nilai pelaksanaan pembelajaran tematik siklus III

\begin{tabular}{|c|c|c|c|c|}
\hline N0. & Rentang & $\begin{array}{c}\text { Jumlah } \\
\text { Peserta }\end{array}$ & Persentase & Sebutan \\
\hline 1. & $91-100$ & 2 & $33 \%$ & Sangat Baik \\
\hline 2. & $79-90$ & 4 & $67 \%$ & Baik \\
\hline 3. & $50-78$ & - & - & Cukup \\
\hline 4. & $0-49$ & - & - & $\begin{array}{c}\text { Perlu } \\
\text { bimbingan }\end{array}$ \\
\hline \multicolumn{2}{|c|}{ Jumlah } & 6 & $100 \%$ & \\
\hline
\end{tabular}

\section{f. Evaluasi dan Refleksi}

Evaluasi pengamatan pelaksananaan pembelajaran tematik pada guru kelas 1 dan kelas 4 pada 3 Sekolah Dasar pada siklus III sudah sedikit ditemukan beberapa kelemahan atau kekurangan skor 2 pada setiap aspek pengamatan.

Dari hasil supervisi klinis dalam pelaksanaan pembelajaran siklus III menunjukkan hasil akhir dari 6 guru, 2 orang guru melaksanakan pembelajaran sangat baik dan 4 guru melaksanakan pembelajaran baik dengan nilai minimum 88, dengan demikian pelaksanaan tindakan dihentikan pada siklus III karena telah mencapai idikator keberhasilan penelitian.

Hasil penelitian tindakan melalui supervisi klinis terhadap kinerja guru dalam pembelajaran tematik kurikulum 2013 pada 3 Sekolah Dasar Kecamatan Gisting, melalui pendampingan supervisi klinis siklus I, II dan III hasil refleksi akhir terjadi peningkatan kinerja guru dalam menyusun RPP tematik dan pelaksanaan pembelajaran tematik kurikulum 2013 dapat diuraikan sebagai berikut:

\section{Penyusunan RPP Tematik}


Hasil kualitas penyusuan RPP tematik siklus I, II dan III tertuang dalam tabel 4.19 berikut:

Tabel 4.19: Nilai Kualitas RPP tematik siklus I, II dan III

\begin{tabular}{|c|c|c|c|c|c|}
\hline \multirow{2}{*}{$\begin{array}{c}\text { N } \\
\text { o }\end{array}$} & \multirow{2}{*}{ Siklus } & \multicolumn{4}{|c|}{ Aktivitas } \\
\cline { 3 - 6 } & & $\begin{array}{l}\text { Sangat } \\
\text { Baik }\end{array}$ & Baik & Cukup & Kurang \\
\hline 1. & Siklus I & - & $33 \%$ & $67 \%$ & - \\
\hline 2. & Siklus II & $17 \%$ & $83 \%$ & - & - \\
\hline 3. & Siklus III & $33 \%$ & $67 \%$ & - & - \\
\hline
\end{tabular}

Kemudian untuk nilai akhir kualitas RPP tematik secara rata-rata siklus I, II dan III dapat dalam tabel 4.20 berikut:

Tabel 4.20: nilai akhir kualitas RPP tematik secara rata-rata siklus I, II dan III

\begin{tabular}{|c|l|c|c|}
\hline No & \multicolumn{1}{|c|}{ Siklus } & Rata-rata & $\begin{array}{c}\text { Peningkatan } \\
\text { kumulatif }\end{array}$ \\
\hline 1. & Siklus I & 77,8 & - \\
\hline 2. & Siklus II & 81,8 & 4,0 \\
\hline 3. & Siklus III & 85,7 & 3,9 \\
\hline
\end{tabular}

Dari data rata-rata nilai akhir penyusunan RPP tematik pada siklus I rata-rata 77,8 , Siklus II rata-rata 81,8 , siklus III rata-rata 85,7 sehingga mengalami peningkatan kumulatif sebesar 7,9

\section{Pelaksanaan Pembelajaran Tematik}

Hasil kualitas pembelajaran tematik siklus I, II dan III setelah dilaksanakan supervisi klinis tertuang dalam tabel 4.21 berikut:

Tabel 4.21: Nilai Kualitas pelaksanaan pembelajaran tematik siklus I, II dan III

\begin{tabular}{|c|c|c|c|c|c|}
\hline \multirow[b]{2}{*}{ No } & \multirow[b]{2}{*}{ Siklus } & \multicolumn{4}{|c|}{ Aktivitas } \\
\hline & & $\begin{array}{c}\text { Sangat } \\
\text { Baik }\end{array}$ & Baik & Cukup & Kurang \\
\hline 1. & $\begin{array}{l}\text { Siklus } \\
\text { I } \\
\end{array}$ & 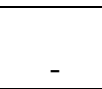 & $17 \%$ & $83 \%$ & 0 \\
\hline 2. & $\begin{array}{l}\text { Siklus } \\
\text { II }\end{array}$ & $17 \%$ & $83 \%$ & - & - \\
\hline 3. & $\begin{array}{l}\text { Siklus } \\
\text { III }\end{array}$ & $33 \%$ & $67 \%$ & - & - \\
\hline
\end{tabular}
pelaksannaan pembelajaran tematik secara rata-rata siklus I, II dan III dapat dalam tabel 4.22 berikut:

Tabel 4.22: Nilai akhir kualitas pelaksannaan pembelajaran tematik secara ratarata siklus I, II dan III

\begin{tabular}{|c|l|c|c|}
\hline No & \multicolumn{1}{|c|}{ Siklus } & Rata-rata & $\begin{array}{c}\text { Peningkatan } \\
\text { kumulatif }\end{array}$ \\
\hline 1. & Siklus I & 77,2 & \\
\hline 2. & Siklus II & 85,7 & 8,5 \\
\hline 3. & Siklus III & 90,7 & 5,0 \\
\hline
\end{tabular}

Nilai rata-rata pelaksanaan pembelajaran tematik Dari data rata-rata nilai akhir pembelajaran tematik pada siklus I rata-rata 77,2, Siklus II rata-rata 85,7 , siklus III rata-rata 90,7 sehingga mengalami peningkatan kumulatif sebesar 13,5.

Dengan adanya peningkatan kinerja guru dalam menyusun RPP tematik dan melaksanaan pembelajaran tematik akibat tindakan perbaikan yang telah dilakukan oleh pengawas sekolah melalui supervisi klinis, yang hal ini telah sesuai pendapat Sahertian (2000: 21) menyebutkan beberapa fungsi supervisi pendidikan dari para ahli yaitu: (a) perbaikan dan peningkatan kualitas pengajaran, (b) membina program pengajaran yang ada sebaik-baiknya sehingga selalu ada usaha, perbaikan, (c) menilai dan memperbaiki faktor- faktor yang mempengaruhi proses pembelajaran peserta didik, (d) mengkoordinasi, menstimulasi, dan mendorong ke arah pertumbuhan profesi guru, (e) memperbaiki situasi belajar mengajar dalam arti yang luas.

Dengan demikian dapat disampaikan bahwa adanya supervisi akademik teknik klinis dapat meningkatkan kinerja guru dalam menyusun RPP dan melaksanakan pembelajaran tematik.

\section{E. KESIMPULAN}

Setelah pelaksanaan tindakan, hasil pengamatan, analisis data dan pembahasan maka dapa disimpulkan bahwa:

1. Adanya peningkatan kinerja guru dalam pembelajaran tematik kurikulum 2013 setelah supervisi akademik dengan teknis klinis pada SD Kecamatan Gisting semester genap tahun pelajaran 2017/2018.

2. Besarnya peningkatan kinerja guru dalam pembelajaran tematik kurikulum 2013 sesudah kegiatan supervisi akademik dengan teknik klinis pada SD Kecamatan Gisting semester genap tahun pelajaran 2017/2018, yaitu kinerja guru dalam menyusun RPP tematik siklus I, II, III mengalami peningkatan kumulatif 7,9 dan kinerja guru dalam pembelajaran tematik mengalami peningkatan kumulatif 13,5.

Dan berdasarkan kesimpulan tersebut maka peneliti memberikan saran kepada Pengawas hendaknya selalu berusaha meningkatkan kualitas pembinaan melalui supervisi akademik untuk meningkatkan kinerja guru; sertaPembinaan terhadap kinerja guru hendaknya dapat dilakukan secara kontinyu oleh kepala sekolah dan pengawas.

\section{Daftar Pustaka}

Gazali, M. (2013). Guru sebagai Garda Terdepan Membangun

Tarbiyah, 28(1), 157-164.

Hajar, I. (2013). Panduan lengkap kurikulum tematik untuk SD/MI. Jogjakarta: Diva Pres. 
Jiwa, I. W., Dantes, N., \& Marhaeni, A. A. I. N. (2013). Pengaruh implementasi pembelajaran tematik terhadap prestasi belajar ditinjau dari motivasi Belajar pada siswa kelas iv gugus empat Di kecamatan gianyar. Jurnal Penelitian dan Evaluasi pendidikan Indonesia, 3.

Mahmudah, M., Muhtarom, M., \& Gusliana, E. (2017). HUBUNGAN PROFESIONALISME GURU DENGAN PRESTASI BELAJAR AL-QUR'AN HADIST SISWA DI MADRASAH TSANAWIYAH GUPPI SUMBEREJO TANGGAMUS. JURNAL MANAJEMEN PENDIDIKAN ISLAM ALIDARAH, 1(1), 10-18.

Nasional, D. P. (2005). Peraturan Pemerintah Republik Indonesia Nomor 19 Tahun 2005 Tentang Standar Nasional Pendidikan. Depdiknas.

Pendidikan, B. S. N. (2007). Standar Proses untuk Satuan Pendidikan Dasar dan Menengah. Badan Standar Nasional Pendidikan.

Sahertian, Piet. 2000. Konsep Dasar dan Teknik Supervisi Pendidikan dalam rangka Pengembangan Sumberdaya Manusia. Jakarta: Rineka Cipta.

Saragih, A. H. (2008). Kompetensi minimal seorang guru dalam mengajar. Jurnal Tabularasa, 5(1), 23-34.

Syafaruddin, 2012.Pendidikan dan Pemberdayaan Masyarakat. Pendidikan Agama Islam Fakultas Tarbiyah Sumatra Utara. Perdana Publishing.

Yunanto, T., \& S Pd, M. M. (2018). Menjadi Guru Profesional. BLACK WHITE. 